\title{
Diagnostic Usefulness of Serum Albumin as a Predictor of Diabetic Ketoacidosis
}

\author{
Jayagowri Karthikeyan, Sujatha Rajaragupathy \\ Department of Biochemistry, PSG Institute of Medical Sciences and Research, Coimbatore, Tamil Nadu, India
}

\section{Abstract}

Context: Diabetes mellitus is one of the most prevalent diseases worldwide. One of the acute complications of diabetes mellitus is diabetic ketoacidosis. It becomes essential for the healthcare physicians to identify the individuals who are likely to be prone to the development of ketosis. Serum albumin levels may be a cost-effective and simple parameter to prognosticate the risk of ketosis. Aims: This study was done to find a relationship between serum albumin levels and ketonuria. Settings and Design: After ethical approval, this prospective case-control study was carried out in patients diagnosed as type-2 diabetes mellitus. Subjects and Methods: Serum albumin levels were measured by bromo cresol green method. Measurement of urine ketones was done manually using dipsticks, a semi-quantitative manual method. Statistical Analysis Used: Student's $t$-test was used to compare continuous variables and Chi-square test for categorical variables. Pearson's correlation was done to establish correlation. Results: In the normoalbuminemic group, $72 \%$ were ketones negative and only $28 \%$ had positive ketones in urine, while in the hypoalbuminemic group, $50.7 \%$ had negative urine ketones and $49.3 \%$ had positive ketonuria. The mean value for ketones in urine was $9.7 \mathrm{mg} / \mathrm{dL}$ in the hypoalbuminemic group, but it was only $4.3 \mathrm{mg} / \mathrm{dL}$ in the normoalbuminemic group. Pearson's correlation between serum albumin and urine ketone levels was performed and the $r$-value was found to be -0.305 . Conclusions: Serum albumin levels may predict the occurrence of ketosis in diabetic patients.

Keywords: Albumin, diabetes mellitus, ketoacidosis

\section{INTRODUCTION}

Diabetes mellitus is one of the most prevalent diseases worldwide. Globally, 415 million people suffer from diabetes mellitus among which many are undiagnosed ${ }^{[1]}$ Due to the impact of people migrating to urban areas and practice of sedentary lifestyle, Asia is now turning out to become the main center of diabetes, especially type- 2 which is one of the leading causes of morbidity and mortality. ${ }^{[2]}$ Apart from the disease, it also presents with enormous number of complications which adds to mortality and morbidity. One of the acute complications of diabetes mellitus is diabetic ketoacidosis (DKA) which is associated with high rates of hospital admissions. It leads to electrolyte and acid-base abnormalities such as metabolic acidosis and dehydration. It can terminate in death in $10 \%$ of individuals. ${ }^{[3]}$ The incidence of ketosis in our population is mainly due to delay in diagnosis or irregular treatment of known diabetic patients. ${ }^{[4]}$ Patients with diabetes mellitus become susceptible to ketosis due to uncontrolled blood glucose levels or precipitating ketosis by infections, surgery, or trauma. ${ }^{[5]}$

\begin{tabular}{|l|l|}
\hline \multicolumn{3}{c|}{ Access this article online } \\
\hline Quick Response Code: & Website: \\
& www.ijccm.org \\
\hline
\end{tabular}

Recent studies focus more on prevention of diseases by predicting its occurrence early. It becomes essential for the healthcare physicians to manage the hyperglycemic crises associated with diabetes. To make it possible, clinicians should initially identify the individuals who are likely to be prone to the development of ketosis. One of the ways to look forward to the occurrence of disease is identifying a biochemical marker which is associated with the incidence of the disease or predisposing factors of the disease. The marker should be easily available, cost-effective, and simple to quantify.

Moreover, with increasing healthcare costs and a changing healthcare system, prevention of DKA remains essential. Identifying diabetic individuals having the risk of ketosis will help physicians prevent emergencies and thereby provide better

Address for correspondence: Dr. Sujatha Rajaragupathy, Department of Biochemistry, PSG Institute of Medical Sciences and Research, Coimbatore, Tamil Nadu, India. E-mail: suja1357@gmail.com

This is an open access journal, and articles are distributed under the terms of the Creative Commons Attribution-NonCommercial-ShareAlike 4.0 License, which allows others to remix, tweak, and build upon the work non-commercially, as long as appropriate credit is given and the new creations are licensed under the identical terms.

For reprints contact: reprints@medknow.com

How to cite this article: Karthikeyan J, Rajaragupathy S. Diagnostic usefulness of serum albumin as a predictor of diabetic ketoacidosis. Indian J Crit Care Med 2018;22:733-6. 
clinical outcome. Individuals identified with the risk of ketosis can be made aware of the preventive measures and immediate medical assistance which can bring down the incidence and mortality rates of DKA.

Serum albumin levels may be one such parameter to prognosticate the risk of ketosis. It is one of the cost-effective and feasible parameters available. It can be performed using simple laboratory techniques and does not require expensive methods or high expertise.

This study was done to find a relationship between serum albumin levels and ketonuria so that albumin may be used to predict DKA. From this study, recent clinical setup will gain albumin as a new marker to assess the risk of diabetic-induced ketosis. This study may also establish a new platform in medical field where a simple and commonly done biochemical analyte will help clinicians to forecast the risk of ketosis in diabetic patients.

\section{Subjects and Methods}

After obtaining approval from the Institutional Human Ethics Committee, this prospective case-control study was carried out in a tertiary care center in South India. Patients diagnosed as type- 2 diabetes based on the American Diabetic Association (ADA) 2016 criteria for more than 1-year duration in general medicine, endocrinology, and diabetology departments during 6 months and for whom blood and urine samples were collected were included in the study. Their personal identifiers such as name, identification number, and other details were concealed. Laboratory investigations such as glycated hemoglobin $(\mathrm{HbA} 1 \mathrm{c})$ and serum creatinine were collected from the Hospital Information System. According to the ADA 2016, the criteria for diabetes are fasting plasma glucose $\geq 120 \mathrm{mg} /$ $\mathrm{dL}$ (fasting is no caloric intake for at least $8 \mathrm{~h}$ ) or 2 -h postprandial glucose $\geq 200 \mathrm{mg} / \mathrm{dL}$ during an oral glucose tolerance test (test should be done as described by WHO, using a glucose load containing the equivalent of $75 \mathrm{~g}$ anhydrous glucose dissolved in water) or $\mathrm{HbA} 1 \mathrm{c} \geq 6.5 \%$ (test should be performed in a laboratory using a method that is National Glycohemoglobin Standardization Program certified and standardized to the Diabetes Control and Complications Trial assay), or in a patient with classic symptoms of hyperglycemia or hyperglycemic crisis, a random plasma glucose $\geq 200 \mathrm{mg} / \mathrm{dL}$. ${ }^{[6]}$ Patients with infection, myocardial infarction, and cerebrovascular events were excluded from the study as they affect the glycemic control. Patients with malignancy and liver and renal diseases were excluded due to their impact on synthesis and excretion of albumin. A sample size of 150 was taken in the study, 75 as hypoalbuminemic and 75 as normoalbuminemic. Serum albumin levels were measured quantitatively and urine ketones were measured semi-quantitatively in the left-over samples of patients who were included. Serum albumin levels were measured by bromo cresol green method which is a semi-automatic quantitative method. Patients with albumin levels $<3 \mathrm{mg} / \mathrm{dL}$ were considered hypoalbuminemic. ${ }^{[7]}$ Based on the serum albumin levels, patients were divided into two groups namely hypoalbuminemic $(<3 \mathrm{~g} / \mathrm{dL})$ and normoalbuminemic $(>3 \mathrm{~g} / \mathrm{dL})$. Measurement of urine ketones was done manually using dipsticks, a semi-quantitative manual method. HbAlc was analyzed using immunoturbidimetric method, and serum creatinine was estimated using alkaline picrate method in Integra 400 Auto-Analyzer in the clinical biochemistry laboratory.

\section{Statistics}

Data were expressed as mean \pm standard deviation, frequencies, and percentages. In statistics, Student's $t$-test was used to compare continuous variables and Pearson's Chi-square test for categorical variables. Cross-tabulation was done for calculation of the odds ratio (OR) and 95\% confidence interval. Pearson's correlation was employed to examine the relationship between clinical variables. $P<0.05$ is considered as statistically significant. The statistical analysis was done using SPSS software version 24 (IBM, Armonk, NY, United States of America).

\section{RESULTS}

The study included 150 diabetic patients, which included $91(60.7 \%)$ males and $59(39.3 \%)$ females. The mean age of the study participants was $58.6 \pm 10.4$ years. The mean $\mathrm{HbA1c}$ of the study population was $9.9 \pm 2.3$ showing that the entire diabetic study population had poor glycemic control. The demographic profiles and baseline characteristics of the study population are listed in Table 1.

The participants were divided into two groups based on their serum albumin levels (75 in each group). A serum albumin level of $3 \mathrm{~g} / \mathrm{dL}$ was considered as cut-off to divide the groups. ${ }^{[7]}$ Based on the baseline characteristics [Table 2], both groups were similar in age, gender, glycemic status, and serum creatinine concentrations.

In the hypoalbuminemic group, 50.7\% had negative urine ketones and $49.3 \%$ had positive ketonuria (traces, small, moderate large), while in the normoalbuminemic group, $72 \%$ were ketones negative and only $28 \%$ had positive ketones in urine. OR was calculated and the difference was found to be statistically significant $(P=0.07)$ [Table 3].

The mean value for ketones in urine was $9.7 \mathrm{mg} / \mathrm{dL}$ in the hypoalbuminemic group, but it was only $4.3 \mathrm{mg} / \mathrm{dL}$ in the normoalbuminemic group $(P=0.01)$ The urine ketone levels above $15 \mathrm{mg} / \mathrm{dL}$ were seen in $31 \%$ of hypoalbuminemic patients but only in $16 \%$ of normoalbuminemic individuals [Table 4 and Figure 1].

\section{Table 1: Baseline characteristics}

\begin{tabular}{lc}
\hline Characteristics & Study population \\
\hline Total number of cases & 150 \\
Males & $91(60.7)$ \\
Females & $59(39.3)$ \\
Mean age (years) & $58.6 \pm 10.4$ \\
Mean HbA1c (\%) & $9.9 \pm 2.3$ \\
\hline
\end{tabular}




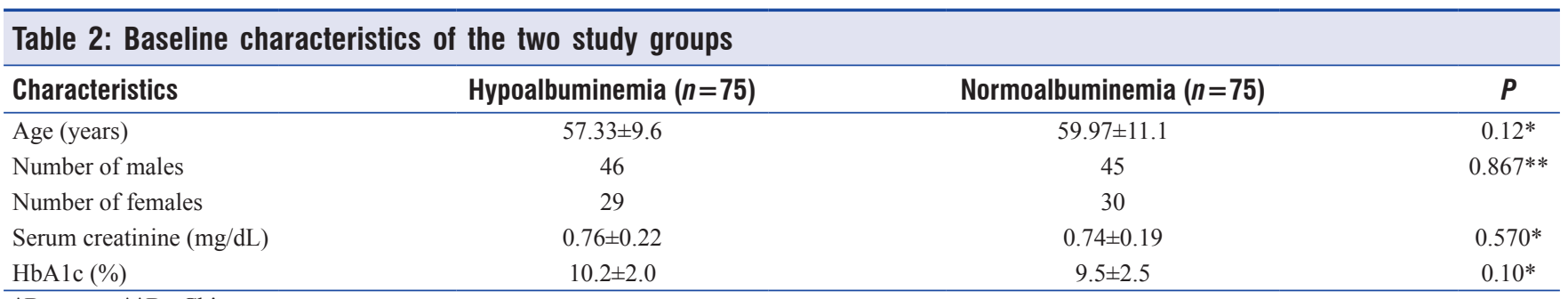

*By $t$-test, **By Chi-square test

\begin{tabular}{lccccc}
\hline \multicolumn{3}{l}{ Table 3: 0 dds ratio calculation } \\
\cline { 1 - 4 } $\begin{array}{l}\text { Urine } \\
\text { ketones }\end{array}$ & \multicolumn{2}{c}{ Albumin levels } & OR & CI & $\boldsymbol{P}$ \\
\cline { 2 - 5 } & Low albumin & Normal albumin & & & \\
\hline Negative & $38(50.7)$ & $54(72)$ & 2.5 & $1.27-4.93$ & $0.007^{*}$ \\
Positive & $37(49.3)$ & $21(28)$ & & & \\
\hline$* P$ value $<0.05$ - significant OR: Odds ratio; CI: Confidence interval
\end{tabular}

\section{Table 4: Comparison of urine ketone levels in the study groups}

\begin{tabular}{lcc}
\hline $\begin{array}{l}\text { Urine ketone } \\
\text { levels }(\mathbf{m g} / \mathbf{d L})\end{array}$ & $\begin{array}{c}\text { Hypoalbuminemia, } \\
\boldsymbol{n}(\%)\end{array}$ & $\begin{array}{c}\text { Normoalbuminemia, } \\
\boldsymbol{n}(\%)\end{array}$ \\
\hline 0 & $38(50.7)$ & $54(72)$ \\
5 & $13(17.3)$ & $9(12)$ \\
15 & $15(20)$ & $8(10.7)$ \\
40 & $7(9.3)$ & $4(5.3)$ \\
80 & $2(2.7)$ & 0 \\
\hline
\end{tabular}

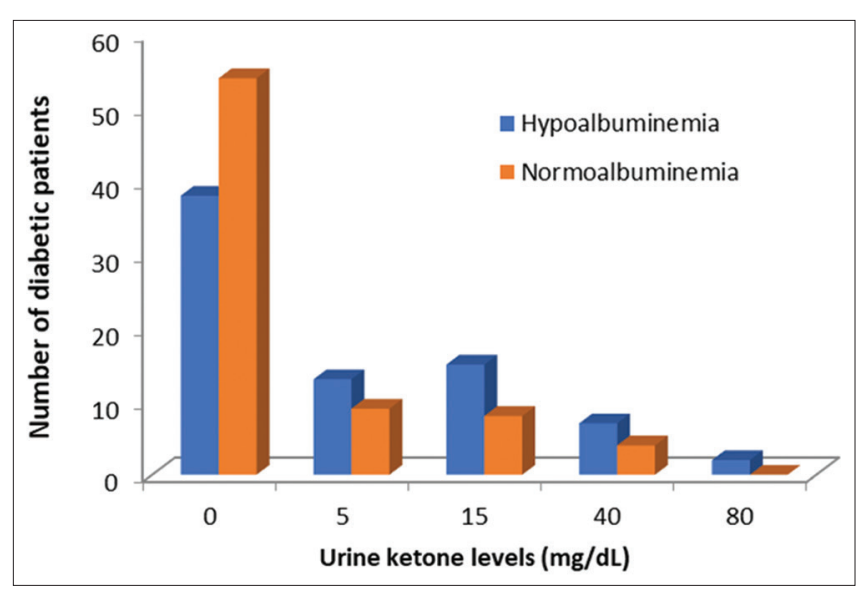

Figure 1: Comparison of urine ketone levels in the study groups

Pearson's correlation between serum albumin and urine ketone levels was performed and the $r$-value was found to be -0.305 $(P<0.001)$ which shows a negative inverse relationship between the two variables.

\section{Discussion}

Mortality and morbidity of diabetes mellitus is mainly due to its complications. DKA, which is one of the acute complications, is a medical emergency. A biomarker to predict DKA is required at the earliest to reduce the mortality due to
DKA. This study serves as an initiative to focus on albumin, a cost-effective and feasible parameter as a predictor of DKA. In a diabetic-prevalent society, more caution should be excised to prevent complications.

In this study, males were predominant (60.7\%) showing that diabetes is more prevalent in males. This was consistent with the results of the study conducted by Shah et al. in which the prevalence rate of males $(17.47 \%)$ was slightly higher than females. ${ }^{[8]}$ This may be because of less sensitivity to insulin and more sedentary lifestyle than females. Obese males have fat deposition in and around viscera while females get peripheral fat deposition. Moreover, the prevalence in males may be due to effects of testosterone or protective effect of estrogens in females.

The mean age of this study population was $58.6 \pm 10.4$ years. A study by Zaman et al. also supports as it stated that diabetes is highly prevalent in the age group of 50-59 years. ${ }^{[9]}$ This may be due to gradual development of insulin resistance, poor metabolic functioning due to aging, or environmental factors such as stress observed in adults.

The mean HbAlc of the entire study population in both the groups was $9.9 \% \pm 2.3 \%$. As both the groups had statistically insignificant difference between their glycemic control, albumin can be used as an independent factor for predicting DKA. Poor glycemic control, which is a cause for DKA, did not interfere in this study.

This study shows $49.3 \%$ of hypoalbuminemic patients having positive urine ketones which were consistent with the results of a study done by Cheng et al. which concluded $48 \%$ hypoalbuminemic patients had ketonuria. ${ }^{[7]}$ One possible explanation is that albumin may be an indicator of insulin reserve in these patients. Hypoalbuminemia may be associated with low insulin levels that precipitate DKA. Another possible theory is that albumin may be a coregulator of ketogenesis along with insulin, glucagon, and other hormones. Albumin may inhibit mitochondrial hydroxymethyl glutaryl CoA synthase enzyme which is the rate limiting enzyme of ketogenesis and thereby decrease production of ketones in insulin-deficient states. In other words, hypoalbuminemia in insulin-deficient conditions removes the inhibition of the enzyme, thereby favoring uncontrolled ketogenesis. When ketone bodies synthesis exceeds breakdown, a diabetic patient presents with DKA. A high proportion of normoalbuminemic patients had no evidence of ketonuria showing evidently that normal albumin levels inhibit ketogenesis. 
The main limitation of this study is the sample size. Diabetes mellitus is a more prevalent disease in developing country like India, and so, larger sample size should be studied for more conclusive results.

The future scope of this study is that it can be carried out in a large sample size with quantitative urine ketone estimation. Follow-up studies may also be conducted to confirm the occurrence of diabetic ketoacidosis in these patients.

\section{Financial support and sponsorship}

The study was supported by ICMR - STS 2017.

\section{Conflicts of interest}

There are no conflicts of interest.

\section{RefEREnCeS}

1. Holman RR. Preface-Diabetes prevention and management. Best Pract Res Clin Endocrinol Metab 2016;30:329.
2. Shaw JE, Sicree RA, Zimmet PZ. Global estimates of the prevalence of diabetes for 2010 and 2030. Diabetes Res Clin Pract 2010;87:4-14.

3. Kao Y, Hsu CC, Weng SF, Lin HJ, Wang JJ, Su SB, et al. Subsequent mortality after hyperglycemic crisis episode in the non-elderly: A national population-based cohort study. Endocrine 2016;51:72-82.

4. Liu B, Yu C, Li Q, Li L. Ketosis-onset diabetes and ketosis-prone diabetes: Same or not? Int J Endocrinol 2013;2013:821403.

5. Du S, Yang X, Shi D, Su Q. Characteristics of type 2 diabetes with ketosis in Baoshan, Yunnan of China. J Diabetes Res 2016;2016:7854294.

6. American Diabetes Association. 2. Classification and diagnosis of diabetes. Diabetes Care 2017;40:S11-24.

7. Cheng PC, Hsu SR, Cheng YC. Association between serum albumin concentration and ketosis risk in hospitalized individuals with type 2 diabetes mellitus. J Diabetes Res 2016;2016:1269706.

8. Shah A, Afzal M. Prevalence of diabetes and hypertension and association with various risk factors among different Muslim populations of Manipur, India. J Diabetes Metab Disord 2013;12:52.

9. Zaman FA, Borang A. Prevalence of diabetes mellitus amongst rural hilly population of North Eastern India and its relationship with associated risk factors and related co-morbidities. J Nat Sci Biol Med 2014;5:383-8. 